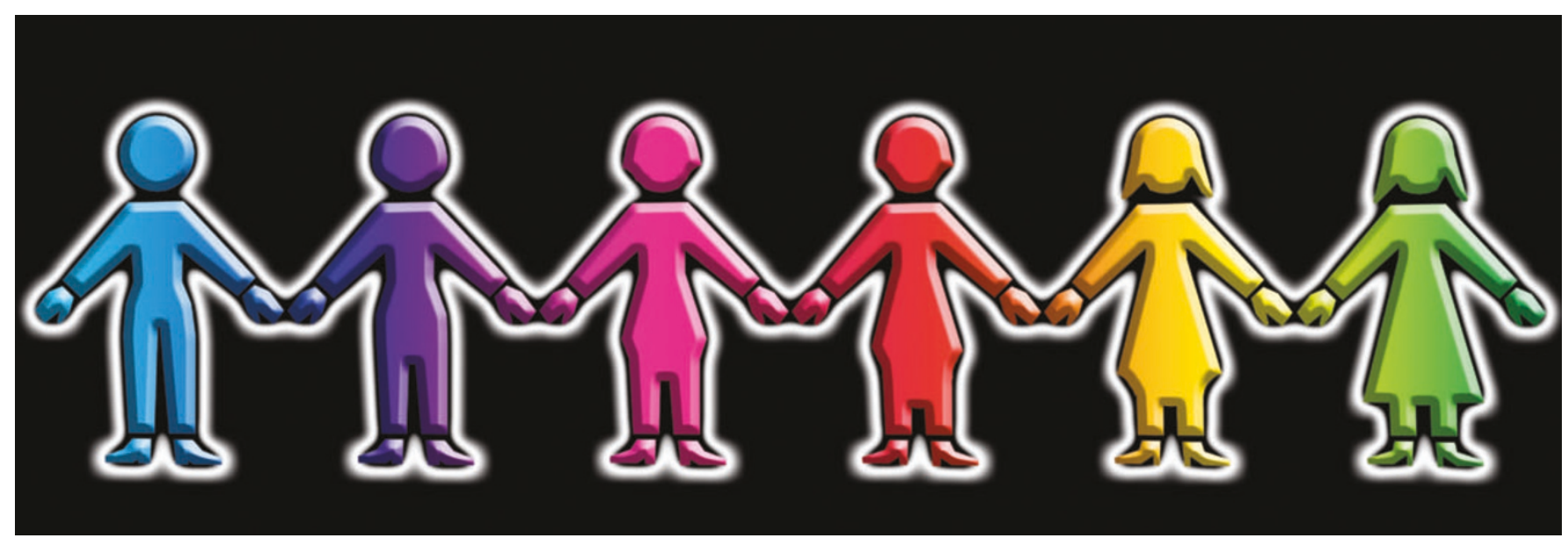

Catastrophes, published by the University of Chicago Press in 1997, show the advantages of identifying authors mentioned, giving full references for cited works, explaining allusions and discussing tricky points. But if the English prose here rarely sparkles, Geoffroy is largely to blame. On style, Cuvier won hands down.

So why should we read these works today? The Cuvier-Geoffroy debate has been given many different meanings, by the two sides at the time and by commentators since. For Le Guyader, molecular developmental biology allows us to recognize Geoffroy as a "visionary of genius" who-Le Guyader realizes it would be grossly anachronistic to call him right was "right to be wrong". A paper from 1822 certainly generates additional interest now that it is cited again. But the deeper reasons why Geoffroy still matters are the approaches that he and Cuvier framed and fought over, rather than any specific answers he gave. Their views decisively shaped our science. Nick Hopwood is in the Department of History and Philosophy of Science, University of Cambridge, Free School Lane, Cambridge CB2 $3 R H, U K$. He is the author of Embryos in Wax: Models from the Ziegler Studio.

\section{Sexual diversity and the gender agenda}

\section{Evolution's Rainbow: Diversity, Gender and Sexuality in Nature and People}

Joan Roughgarden

University of California Press: 2004. 472 pp. $\$ 27.50, £ 18.95$

\section{Sarah Blaffer Hrdy}

Rather than being one coherent book, the narrative of Evolution's Rainbow shuttles between three interwoven agendas. The first is a passionate cry from the heart for greater understanding of sexual diversity in nature and greater tolerance for the many gay men, lesbians, bisexuals, transgenders and others who do not fit comfortably into male or female binary categories.

The author, eminent Stanford biologist Joan Roughgarden, who is herself a transgendered woman previously known as John, cites poignant case studies that illustrate the anguish leading up to decisions to switch genders. As one such transgendered woman put it: "I've laid everything I've achieved in life — job, relationship, family, health, future - on the table, and it seems fate will decide what I am allowed to keep, if anything. It's kind of like starting life all over again." Roughgarden even includes rare practical advice on how to inform your boss that you intend to switch genders without losing your job. Few readers of Nature will disagree with the main tenets of what is essentially a human-rights agenda, even if they don't agree with all of Roughgarden's interpretations or policy recommendations.

The second, and for me most interesting, book-within-a-book provides a cornucopia of information about sex and gender diversity across human societies and the natural world. There are vignettes about homosexuals in Ancient Greece, eunuchs in Rome, hijras in India, and Native American 'two-spirits'. Roughgarden then takes us on a whirlwind tour through the zoological counterpart of human gender studies, introducing fish that change from females into males; intersex kangaroos that have a penis as well as a pouch equipped with mammary glands; kangaroo rats, in which up to $16 \%$ of a population have both sperm- and eggrelated plumbing; intersex bears that give birth through the penis; hermaphroditic whales; and homosexual black swans that turn out to be more successful at rearing young than their heterosexual counterparts.

For those familiar with the literature on sex differences, some of these gender-bending examples will be old hat, others quite new. A few sections are dazzlingly original, such as Roughgarden's imagined memoir of her own embryonic development. Wherever possible, she emphasizes the naturalness of gender gradations. She estimates that one in a thousand people are transgendered.
Iconoclastically, Roughgarden suggests that transsexuality is unlikely to be an anomaly: throughout the book, she is at pains to suggest ways in which gender ambiguity (such as feminine-seeming male fish) might be adaptive.

As a compendium of information on sex and gender diversity in the natural world, Roughgarden's is the richest and most authoritative book available, fulfilling a desperate need of readers both within and outside the scientific community. For readers craving information about transgendered existences, or for those like me who are deeply moved by Gay Pride parades and the social transformations that they represent, this book is going to have a huge impact. This is why I wish the third agenda had been more carefully considered.

In what Roughgarden herself views as the main message of the book, she lays out her reasons for rejecting Darwin's theory of sexual selection, as well as her grounds for an "indictment of academia for suppressing and denying diversity". The "facts of nature", she claims, falsify darwinian theory. She stresses instead that sex is essentially cooperative, is not a battle and often does not lead to conception. "We are only just realizing," she writes, "that the concepts of gender and sexuality we grew up with are seriously flawed." She argues that Darwin's theory of sexual selection is so flawed that it should be replaced by a theory of her own. However, I am less impressed by her critiques and alternative theory than by her timing. This evolutionary biologist becomes a woman, and only then do the problems occur to her?

It is a bad idea, argues Roughgarden, to move from a binary gender system based on gamete size (large eggs and small sperm) to explanations about differences in male and female body sizes, behaviours or mating strategies. It is ill advised, she says, to stereotype males as sexually ardent and females as coy; to ignore social or ecological constraints on female choice; to overemphasize genes at the expense of social or developmental contexts; or to give precedence to quests for supposedly the 'best' genes at the 
expense of non-conceptive strategies that animals might be pursuing. I could not agree more. But there is a Rip Van Winkle quality to all this.

Far from being "just realized", these problems were discussed in the 1970s and 1980 s by female sociobiologists, who called for a broadening of evolutionary theories to include selection pressures at more levels and on a broader range of individuals (such as females and juveniles). Roughgarden mentions some of these critiques in passing, but without exploring the impact that such findings are already having. Even though the push for revisions began on the margins of evolutionary theorizing, change (however inefficiently reached) came from within. This process is representative of how science works. Over the long haul, researchers (especially young ones) have less to gain from suppressing information about diversity than from making their reputations by exploring it

Yes, it took a long time. But once the previously marginalized (Katherine Ralls, Mary Jane West-Eberhard, Patricia Adair Gowaty, Barbara Smuts and myself, to name only a few) had gained enough influence to be heard, evolutionary horizons began to broaden. Far from trying to suppress our

\section{High points in geology}

Devil in the Mountain: A Search for the Origin of the Andes

by Simon Lamb

Princeton University Press: 2004. 336 pp.

$\$ 29.95, £ 19.95$

\section{David E. James}

Devil in the Mountain is the fascinating story of geologist Simon Lamb's quest to understand how the high Andes formed. It includes a wealth of real-life, even harrowing, anecdotes of fieldwork, mixed with colourful descriptions of Bolivian culture. This engrossing and well-written book focuses on deciphering how the modern Andes, and high mountains in general, took shape on the surface of the Earth. Lamb parses the Andean story for us, piece by piece, as he came to understand the process. The reader travels with him by Toyota Land Cruiser through the Bolivian Andes as he sorts through the clues to their growth. We share with him his experiences in New Zealand and Scotland, his opportune conversations with fellow scientists, and a host of other disparate threads that became the building blocks of his understanding of how high mountains are formed.

The story unfolds in the central Andes, the highest and widest part of the Andean chain that runs the length of western South views, new generations of sociobiologists rushed past us to explore the expanding frontiers. Theories that were never so much false as incomplete and overextended are already beginning to be revised. Roughgarden's book will similarly galvanize research in the transsexual realm of the great continuum of diversity out there.

But I fear that her book may also mislead readers on two counts. First, competition between those of one sex for reproductive access to the other remains a robust explanatory framework, even though it is not the whole story. Second, I fear that Roughgarden's "indictment" will fuel widespread misunderstandings about the way in which scientists operate.

Unquestionably, many medical professionals were slow to understand what being transgendered means. Lives were sacrificed to dogmatic surgical and psychological interventions. Some hopelessly unreflective scientists continue to "sneak gender stereotypes into the primary scientific literature and corrupt its objectivity", aided and abetted by sloppy popularizers. Raising the consciousness of darwinists is taking longer than ideally it might have. Nor have evolutionary biologists always been candid in acknowledging either the sources of our biases or how such biases came to be corrected. Evolutionary biology does indeed have its share of die-hard dogmatists.

But the biases that Roughgarden highlights have less to do with false theories or cover-ups than with the occupational hazards of being human, of tending to see what we expect (or sometimes want) to see and incorporating prejudiced observations into our starting assumptions. Empathy (just whose interests we identify with) plays a much greater role in the biological and social sciences than is generally acknowledged. It is even possible that learning biases are built into human psychology, preventing us from noticing things counter to our own (including our gender's) interests. But these are not reasons to reject sexual-selection theory; they are merely reasons to encourage diversity among those applying it, the better to study nature's rainbows, sexual and otherwise. Hopefully, Roughgarden's book will be one more step towards that goal.

Sarah Blaffer Hrdy is professor emeritus in the Department of Anthropology, University of California, Davis, California 95616, USA. Her most recent book is Mother Nature: A History of Mothers, Infants, and Natural Selection.

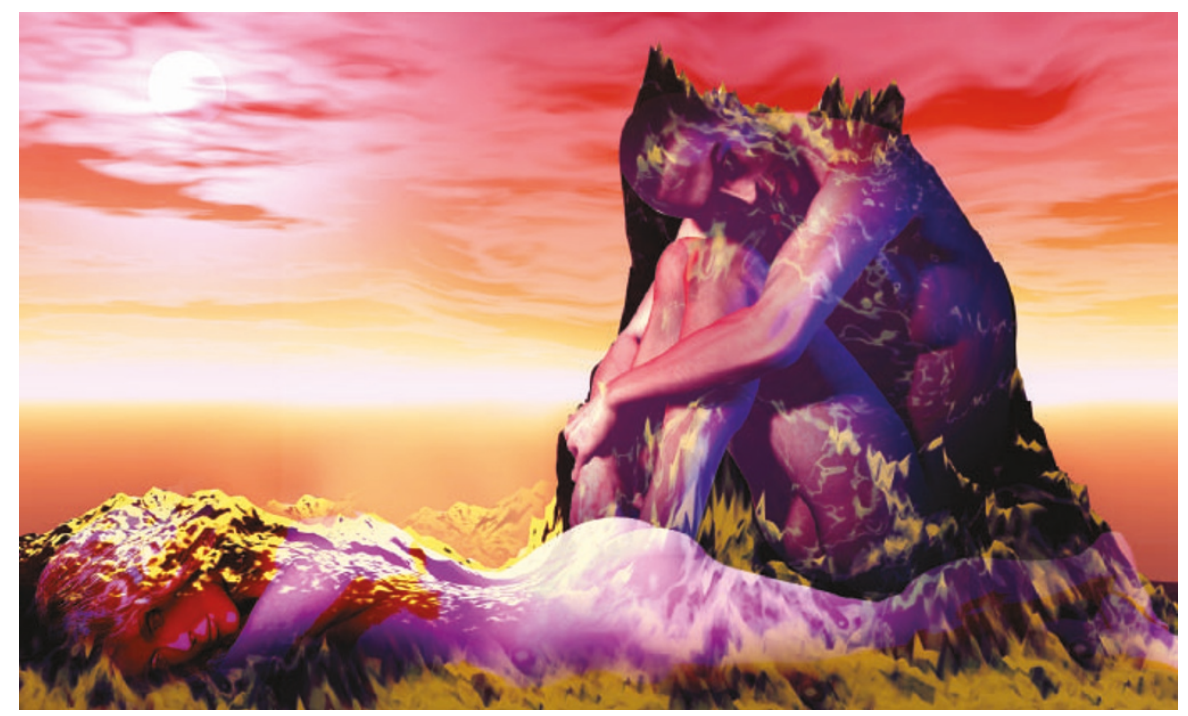

America. Here the great volcanic peaks of the Western Cordillera and the tectonically folded and faulted ranges of the high Eastern Cordillera are split from one another by one of the world's greatest plateaux, the altiplano, situated an imposing 4,000 metres above sea level. Lamb staked out his territory in 1989 in the Eastern Cordillera of Bolivia, and he and his students embarked on a protracted study to understand what drove the Andes to such great heights.

Lamb begins by explaining how he came to study the Andes in the first place, and the origins of the book's title - a reference to the evil underground spirits that Bolivian miners believe decide the fate of each mine, and which they appease with a statue and offerings at the mine entrance. Then we divert to northern Scotland where Lamb introduces the enigma not just of mountain building but of Earth's evolution itself, starting with the early scientific breakthroughs that revealed deep geologic time and thence along the tortuous path of scientific ideas to the dawn of plate tectonics. The narrative of Lamb's own journey of discovery is inextricably linked to plate tectonics, which lies at the heart of all understanding of the Andes.

Lamb's writing is engaging and clear, making for a thoroughly accessible book. He is at his best showing how geologists decipher the clues hidden in outcrops and the 